\title{
Epidemiology of ocular emergencies in the Egyptian population: a five-year retrospective study
}

This article was published in the following Dove Press journal:

Clinical Ophthalmology

I2 July 20 I I

Number of times this article has been viewed

\author{
Hany E El-Mekawey' \\ Khaled G Abu El Einen' \\ Mohammad Abdelmaboud' \\ Amr Khafagy' \\ Eman M Eltahawy ${ }^{2}$ \\ 'Department of Ophthalmology, \\ Faculty of Medicine, Cairo University, \\ ${ }^{2}$ National Research Center, Cairo, \\ Egypt
}

Background: The purpose of this study was to determine the epidemiology of ocular lesions seen in the ophthalmic casualty room of the largest referral hospital in Egypt over 5 years from 2004 to 2008.

Methods: This epidemiologic database study used the medical records at Cairo University Hospital. Data were recorded using the ICD10 classification. Statistical analysis was based on diagnosis, age, gender, residential area, and year of admission.

Results: Over 5 years, 8361 ocular emergencies were admitted as inpatients. Open globe injuries were the most prevalent, comprising $33.46 \%$ of emergencies. Most cases were males $(69 \%)$, in whom the most frequent lesions were open globe injuries, infective keratitis, and lid injuries. The most common ocular emergencies in females were open globe injuries, infective keratitis, endophthalmitis, and glaucoma. The age group 6-16 years accounted for $24 \%$ of emergencies, and patients over 45 years accounted for $26.8 \%$. Under the age of 45 years, the most common lesions were open globe injuries (36\%), and over this age, the most common lesions were infective keratitis (34.4\%). Patients from Upper Egypt accounted for 56.2\% of emergencies. A superficial corneal foreign body was the most common reason for attending the ophthalmic casualty room, with 24,844 cases seen over the 5 years of the study, all of which were managed as outpatient procedures. Deep corneal foreign bodies were more common than intraocular foreign bodies. The most common ocular hemorrhage was hyphema. The most common type of glaucoma was acute angle closure.

Conclusion: Superficial corneal foreign bodies, open globe injuries, and infective keratitis are the main ocular emergencies seen in the Egyptian population. Corneal foreign bodies are mostly the result of occupational accidents in workers not wearing protective goggles. Violent altercations (41.9\%), occupational accidents (26.3\%), and motor vehicle accidents (24.4\%) were the main circumstances involved in open globe injuries. The most common admissions were for open globe injuries under the age of 45 years and infective keratitis above this age. Upper Egypt was the main referring geographic area.

Keywords: ocular casualties, foreign body, open globe, infective keratitis, lid injuries

\section{Introduction}

Ocular casualties are an important cause of preventable monocular blindness. However, little information is available regarding their epidemiology in developing countries. ${ }^{1-6}$ This study analyzed the pattern of ocular lesions attending the casualty room of the biggest referral hospital in Egypt over a 5-year period. Previous studies of ocular trauma in Egypt have been of short duration, and the most recent reported cases were for the year 2000..$^{5}$ So far, this is the largest study of ocular emergencies in Egypt.
Correspondence: Hany E El-Mekawey I5 Naser Street from Fatma Roshdy Street, Alharam, Giza, Egypt

Tel +2020105206012

Fax +2 0239767329

Email hany_elmekawey@yahoo.com 


\section{Methods}

This epidemiologic database study used medical records during 2004-2008 from the ophthalmic casualty room at Cairo University Hospital. We used ICD10 classification to record data and SPSS17 software for statistical analysis, based on simple description of casualty load, according to diagnosis, age, gender, residential area, and year of admission. The authors adhered to the guidelines of the Declaration of Helsinki. Cairo University Hospital is the largest referral center for ocular emergencies in Egypt. Other hospitals and ophthalmic centers in Egypt do not treat ocular emergencies because of potential medicolegal problems, poor postoperative outcomes of severe trauma, and the possibility of multiorgan injury in casualties. The emergency unit at Cairo University Hospital is equipped to manage emergencies and usually receives several accidents at a time. All emergency specialties are represented, so that any multiorgan trauma can be managed.

\section{Results}

Over the 5 years of the study, 8361 ocular emergencies were admitted as inpatients. Open globe injuries (33.46\%) were the most frequent (Tables 1 and 3, Figure 1). For open globe injuries, $76.7 \%$ of patients were males and $23.3 \%$ were females; $43.75 \%$ of cases were under the age of 30 years, $28.27 \%$ were aged $30-45$ years, and $13.63 \%$ were older than 45 years, with $57.5 \%$ of open globe injuries coming from Upper Egypt (Figure 2), 23.6\% from the urban governorate, and $18.4 \%$ from Lower Egypt. Violent altercations were responsible for $41.9 \%$ of open globe injuries. Occupational accidents were responsible for $80.6 \%$ of intraocular foreign bodies $(n=108)$ and $26.3 \%$ of open globe injuries. Reluctance to wear or lack of protective goggles was the main cause of occupational open globe injuries among industrial and construction workers. Motor vehicle accidents were responsible for $24.4 \%$ of open globe injuries, and domestic

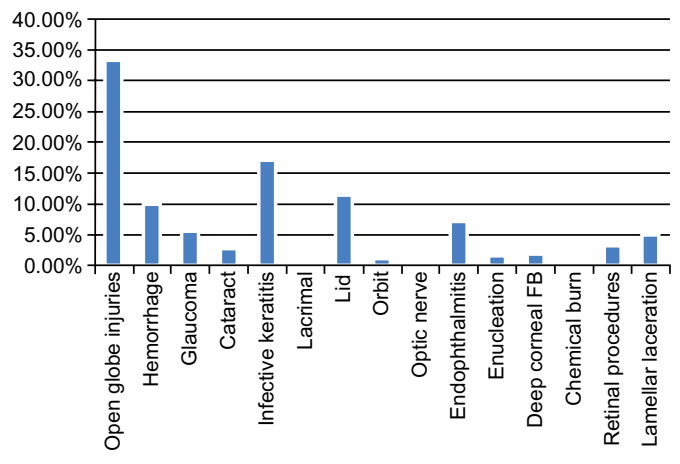

Figure I Proportions of ocular emergencies.

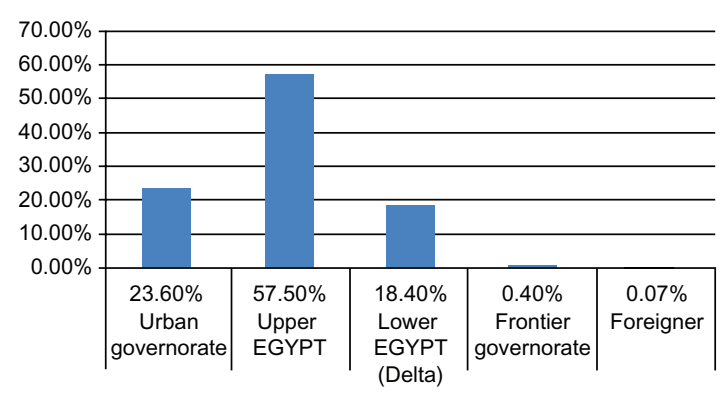

Figure 2 Distribution of open globe injuries among governorates.

accidents were responsible for $7.4 \%$. Other emergencies, in order of frequency, were infective keratitis, lid injuries, ocular hemorrhage, endophthalmitis, glaucoma, lamellar laceration, retinal procedures, lens-related lesions, deep corneal foreign bodies, enucleation, orbital lesions, uveitis, optic nerve lesions, severe chemical burns, and lacrimal lesions (Tables 1 and 3, Figure 1). Closed globe injuries were found for 1365 eyes (16.3\%), comprising 811 ocular hemorrhages (9.7\%), 387 lamellar lacerations (4.6\%), 158 deep corneal foreign bodies $(1.9 \%)$, and nine chemical burns $(0.1 \%)$.

The highest number of ocular emergencies occurred in patients under 16 years of age, followed by those over 45 years. Those aged $31-45$ years recorded the least number of ocular emergencies (Table 1). Open globe injuries, lid injuries, ocular hemorrhage, infective keratitis, and lamellar laceration were most prevalent in children younger than 5 years. Open globe injuries, ocular hemorrhage, lid injuries, and lamellar laceration were the most prevalent in the age group 6-16 years. Open globe injuries, lid injuries, infective keratitis, and ocular hemorrhage were most prevalent in the age group 17-30 years. Open globe injuries, corneal abscess, lid injuries, endophthalmitis, acute glaucoma, and ocular hemorrhage were the most prevalent in the age group 31-45 years. Infective keratitis, endophthalmitis, open globe injuries, and acute glaucoma were most prevalent in patients aged over 45 years.

Males accounted for $69 \%$ of ocular emergencies. The most common ocular emergencies in males were open globe injuries (37.2\%), infective keratitis (15.3\%), and lid injuries $(12.3 \%)$. The most common ocular emergencies in females were open globe injuries (25.15\%), infective keratitis (21.1\%), endophthalmitis (10.2\%), and glaucoma (10.1\%). Regarding residential area, Upper Egypt had the highest number of ocular emergencies and admissions (Table 2).

Open globe injuries were most prevalent in all governorates (Figure 2). Other lesions, in order of frequency, were lid injuries (14.9\%) and infective keratitis (14.7\%) in urban governorates, infective keratitis (16.1\%), lid injuries (10.8\%), 
Table I Distribution of ocular emergencies according to age group

\begin{tabular}{|c|c|c|c|c|c|c|c|c|c|c|c|c|}
\hline \multirow[t]{2}{*}{ Ocular emergency } & \multicolumn{2}{|c|}{$0-5$ years } & \multicolumn{2}{|c|}{$6-16$ years } & \multicolumn{2}{|c|}{$17-30$ years } & \multicolumn{2}{|c|}{$3 I-45$ years } & \multicolumn{2}{|c|}{ Above 45 years } & \multicolumn{2}{|c|}{ Total } \\
\hline & $n$ & $\%$ & $\mathbf{n}$ & $\%$ & $n$ & $\%$ & $\mathbf{n}$ & $\%$ & $\mathbf{n}$ & $\%$ & $\mathbf{n}$ & $\%$ \\
\hline $\begin{array}{l}\text { Open globe injuries } \\
\text { (including IOFB) }\end{array}$ & 474 & 42.97 & 891 & 44.48 & 779 & 43.79 & 348 & 28.27 & 306 & 13.63 & 2798 & 33.46 \\
\hline Infective keratitis & 78 & 7.1 & 93 & 4.6 & 186 & 10.5 & 303 & 24.6 & 772 & 34.4 & 1432 & 17.1 \\
\hline Lid & 190 & 17.2 & 253 & 12.6 & 278 & 15.6 & 122 & 9.9 & 84 & 3.7 & 927 & 11.1 \\
\hline Hemorrhage & 82 & 7.4 & 380 & 19.0 & 160 & 9.0 & 76 & 6.2 & 113 & 5.0 & 811 & 9.7 \\
\hline Endophthalmitis & 45 & 4.1 & 71 & 3.5 & 62 & 3.5 & 81 & 6.6 & 340 & I5.I & 599 & 7.2 \\
\hline Glaucoma & 16 & 1.5 & 40 & 2.0 & 47 & 2.6 & 77 & 6.3 & 290 & 12.9 & 470 & 5.6 \\
\hline Lamellar laceration & 70 & 6.3 & 123 & 6.1 & 97 & 5.5 & 51 & 4.1 & 46 & 2.0 & 387 & 4.6 \\
\hline Retinal procedures & 40 & 3.6 & 20 & 1.0 & 39 & 2.2 & 75 & 6.1 & 75 & 3.3 & 249 & 3.0 \\
\hline Cataract & 22 & 2.0 & 48 & 2.4 & 42 & 2.4 & 31 & 2.5 & 74 & 3.3 & 217 & 2.6 \\
\hline Deep corneal FB & 46 & 4.2 & 40 & 2.0 & 37 & 2.1 & 24 & 1.9 & 11 & 0.5 & 158 & 1.9 \\
\hline Enucleation & 5 & 0.5 & 12 & 0.6 & 10 & .6 & 20 & 1.6 & 99 & 4.4 & 146 & 1.7 \\
\hline Orbit & 26 & 2.4 & 13 & 0.6 & 28 & 1.57 & 14 & 1.14 & 26 & 1.2 & 107 & 1.24 \\
\hline Optic nerve & 2 & 0.2 & 5 & 0.2 & 2 & 0.1 & 5 & .4 & 5 & 0.2 & 19 & 0.2 \\
\hline Chemical burn & 2 & 0.2 & 3 & 0.1 & 3 & 0.2 & 1 & 0.1 & 0 & 0.0 & 9 & 0.1 \\
\hline Lacrimal & I & 0.1 & 1 & 0.0 & 5 & 0.3 & 1 & 0.1 & 2 & 0.1 & 10 & 0.1 \\
\hline Total & 1103 & 100 & 2003 & 100 & 1779 & 100 & $|23|$ & 100 & 2245 & 100 & 8361 & 100 \\
\hline
\end{tabular}

Abbreviations: IOFBs, intraocular foreign bodies; FB, foreign body.

and ocular hemorrhage (10.2\%) in Upper Egypt. Infective keratitis $(23.7 \%)$ was most common in the delta region of Lower Egypt, with a rate of 52.93\% in Upper Egypt, 24.30\% in Lower Egypt, and 22.28\% in the urban governorate.

Over the 5 years of study, the most prevalent ocular emergencies were open globe injuries, infective keratitis, and lid injuries (Table 3). Superficial corneal foreign body was estimated to be the most common reason for attending the ophthalmic casualty room and was managed as an outpatient procedure. The cause was occupational injury in $98.7 \%$ of cases (metal and construction workers), an outdoor injury in $0.9 \%$, and a domestic injury in $0.4 \%$. An average of 4968.8 superficial corneal foreign bodies were removed per year and an average of 13.6 were removed per day (totaling 24,844 over the 5 -year study period). Only 295 (1.17\%) of the foreign body cases were admitted as inpatients. The most common cause for admission due to foreign body (Table 4) was deep corneal foreign body followed by intraocular foreign body. Posterior segment foreign bodies accounted for most of the intraocular foreign bodies. The most common cause of deep corneal and intraocular foreign bodies was occupational (in industrial and construction workers) followed by firearm injuries; $80.6 \%$ of intraocular foreign bodies $(n=108)$ were due to occupational injury and $19.4 \%$ $(n=26)$ were due to firearm injuries. Orbital foreign bodies were also due to firearm injuries. In all occupational foreign body injuries, the subjects did not wear eye protection. The most frequent causes of ocular hemorrhage, glaucoma, and lens emergencies were hyphema, acute angle-closure glaucoma, and traumatic cataract, respectively (Table 5).

Ocular nonemergencies accounted for $10.4 \%$ of admissions via the casualty room. The younger the patients, the more likely they were to present with a nonurgent lesion. Of the nonurgent cases, 64\% were younger than 16 years (Table 6), and $16.7 \%$ of admitted cases in this age group were nonurgent. The main reasons for admission were removal

Table 2 Distribution of ocular admissions according to governorate

\begin{tabular}{|c|c|c|c|c|c|c|c|}
\hline \multirow[t]{2}{*}{ Governorate } & \multicolumn{2}{|c|}{ Emergency } & \multicolumn{2}{|c|}{ Nonemergency } & \multicolumn{2}{|c|}{ Total } & \multirow[t]{2}{*}{$P$ value } \\
\hline & $\mathbf{n}$ & $\%$ & $\mathbf{n}$ & $\%$ & $\mathbf{n}$ & $\%$ & \\
\hline $\begin{array}{l}\text { Urban (Cairo, Alexandria, } \\
\text { Suez, Port Said) }\end{array}$ & 2171 & 26.0 & 224 & 23.0 & 2395 & 25.7 & 0.186 \\
\hline Upper Egypt & 4697 & 56.2 & 577 & 59.2 & 5274 & 56.5 & \\
\hline Lower Egypt & 1466 & 17.5 & $|7|$ & 17.6 & 1637 & 17.5 & \\
\hline $\begin{array}{l}\text { Frontier (North, South Sinai, } \\
\text { New Valley, Matrouh) }\end{array}$ & 23 & 0.3 & 1 & 0.1 & 24 & 0.3 & \\
\hline Foreign & 4 & 0.0 & I & 0.1 & 5 & 0.1 & \\
\hline Total & 8361 & 100.0 & 974 & 100.0 & 9335 & 100.0 & \\
\hline
\end{tabular}


Table 3 Distribution of ocular emergency admissions for 2004-2008

\begin{tabular}{|c|c|c|c|c|c|c|c|c|c|c|c|c|}
\hline \multirow[t]{2}{*}{ Emergency } & \multicolumn{2}{|c|}{2004} & \multicolumn{2}{|c|}{2005} & \multicolumn{2}{|c|}{2006} & \multicolumn{2}{|c|}{2007} & \multicolumn{2}{|c|}{2008} & \multicolumn{2}{|c|}{ Total } \\
\hline & $\mathbf{n}$ & $\%$ & $\mathbf{n}$ & $\%$ & $\mathbf{n}$ & $\%$ & $\mathbf{n}$ & $\%$ & $\mathbf{n}$ & $\%$ & $\mathbf{n}$ & $\%$ \\
\hline Open globe injuries & 526 & 34.7 & 559 & 33.5 & 529 & 30.4 & 608 & 33.5 & 576 & 35.6 & 2798 & 33.46 \\
\hline Infective keratitis & 196 & 12.9 & 307 & 18.4 & 316 & 18.1 & 332 & 18.3 & 281 & 17.3 & 1432 & 17.1 \\
\hline Lid & 126 & 8.3 & 168 & 10.1 & 221 & 12.7 & 211 & 11.6 & 201 & 12.4 & 927 & II.I \\
\hline Hemorrhage & 158 & 10.4 & 157 & 9.4 & 185 & 10.6 & 176 & 9.7 & 135 & 8.3 & 811 & 9.7 \\
\hline Glaucoma & 101 & 6.7 & 95 & 5.7 & 88 & 5.1 & 106 & 5.8 & 80 & 4.9 & 470 & 5.6 \\
\hline Cataract & 53 & 3.5 & 45 & 2.7 & 39 & 2.2 & 44 & 2.4 & 36 & 2.2 & 217 & 2.6 \\
\hline
\end{tabular}

of sutures (55\%), examination under anesthesia (10.37\%), keratoplasty $(5.95 \%)$, pterygium $(4.2 \%)$, and retinal procedures $(1.23 \%)$.

Enucleation was done for 150 eyes, comprising 107 blind painful eyes, five severely damaged eyes with retained nonmagnetic intraocular foreign bodies, seven eyes with retinoblastoma (two presenting with glaucoma), and 31 eyes with melanoma (two presenting with glaucoma). Evisceration was done for 235 cases with panophthalmitis and 32 cases with endophthalmitis. Of the 599 endophthalmitis/ panophthalmitis cases, $226(37.7 \%)$ were postoperative, $261(43.57 \%)$ were post-traumatic, and 112 (18.7\%) were associated with corneal abscess.

\section{Discussion}

This is the largest and most recent epidemiological study of ocular trauma in Egypt, and the first to investigate ocular emergencies. The study included a 5-year observation period, from 2004 to 2008 . The male to female ratio was about 2:1. Most injuries were attributable to outdoor activity, occupational exposure, drug abuse, dangerous sports, hobbies, and violent behavior. ${ }^{4,7-12}$ As in the literature, open globe injuries were the most frequent injuries in males and females from all provinces. ${ }^{4,13,14}$ Of the open globe injuries, 134 were intraocular foreign bodies (1.6\%) and 2664 (31.9\%) involved

Table 4 Foreign body injuries

\begin{tabular}{lll}
\hline Foreign bodies & $\mathbf{n}$ & $\%$ \\
\hline Corneal foreign bodies & 25,002 & 100 \\
Superficial & 24,844 & 99.37 \\
Deep corneal & 158 & 0.63 \\
- Industrial I38 (87.34\%) & & \\
- Firearm 8 (5.06\%) & & \\
- Agricultural 7 (4.43\%) & & \\
- Domestic 5 (3.16\%) & 134 & 100 (4.8\% of open \\
Intraocular foreign bodies & & globe injuries) \\
- Posterior segment & 121 & 90.9 \\
- Anterior segment & 13 & 9.1 \\
Orbital foreign bodies & 3 & \\
\hline
\end{tabular}

ruptured, penetrated, or perforated globes. Our files did not use Birmingham Eye Trauma Terminology, and we discovered that ruptured, penetrated, and perforated globes were mostly documented as "rupture globes" by resident staff. Therefore, our retrospective study could not differentiate between these types of presentations. In an Egyptian study of ocular trauma in $2000,{ }^{5}$ there were $123(80.4 \%)$ open globe injuries and 30 (19.6\%) closed globe injuries. Of the open globe injuries, 48 eyes (31.4\% of all eyes) were ruptured globes and 75 eyes ( $49 \%$ of all eyes) were lacerated globes ( 37 intraocular foreign bodies, 35 penetrating injuries, and three perforating injuries, ie, $24 \%, 23 \%$, and $2 \%$, respectively, of all eye injuries). However, these data were from a prospective epidemiological and clinical study of ocular trauma over a six-month period. Our study was retrospective, based on a computer database over 5 years, and included all emergency ocular admissions.

The pattern of ocular emergencies varied according to patient age (Table 1). Under 30 years, open globe injuries, lid injuries, and ocular hemorrhage were most common, reflecting high exposure to trauma. From 31 to 45 years,

Table 5 Ocular hemorrhage, glaucoma, and cataract cases admitted via casualty room

\begin{tabular}{|c|c|c|}
\hline & $\mathbf{n}$ & $\%$ \\
\hline \multicolumn{3}{|l|}{ Ocular hemorrhage } \\
\hline Hyphema & 720 & 88.8 \\
\hline Conjunctival hemorrhage and chemosis & 85 & 10.5 \\
\hline \multicolumn{3}{|l|}{ due to blunt trauma for exploration } \\
\hline Vitreous and retinal hemorrhage & 6 & 7 \\
\hline \multicolumn{3}{|l|}{ Glaucoma } \\
\hline Acute angle closure glaucoma & 356 & 75.7 \\
\hline Neovascular glaucoma & 44 & 9.4 \\
\hline Glaucoma due to traumatic hyphema & 36 & 7.7 \\
\hline Glaucoma with cataract (phacomorphic, & 21 & 4.5 \\
\hline \multicolumn{3}{|l|}{ phacolytic, and anterior dislocation) } \\
\hline Buphthalmous, congenital glaucoma & 9 & 1.9 \\
\hline Malignant melanoma & 2 & 0.4 \\
\hline Retinoblastoma & 2 & 0.4 \\
\hline \multicolumn{3}{|l|}{ Cataract } \\
\hline Traumatic cataract and dislocated lens & 209 & 96.3 \\
\hline Lens replacement & 8 & 3.7 \\
\hline
\end{tabular}


open globe injuries were the most prevalent, followed by corneal abscess reflecting agricultural accidents. Above the age of 45 years, infective keratitis was the most frequent ocular emergency, followed by endophthalmitis and open globe injuries.

Previous studies have found the highest rates of ocular trauma in young males. ${ }^{4,13,15-17}$ However, our study found a bimodal peak incidence of ocular emergency in the age group 6-16 years (24\% of ocular emergencies) and above 45 years (26.8\% of ocular emergencies). These findings are in agreement with the reported literature on incidence of ocular trauma, given that the first peak was related to trauma in young males, while the second peak was related to infective keratitis in elderly patients.

As universal in the literature, primary management of open globe injuries involved suture of the wound, with excision, repositioning of prolapsed contents, or lensectomy. ${ }^{4}$ The younger the patients, the more likely they were to attend for a noncasualty lesion. Children were admitted for suture removal and examination under anesthesia. The percentage of nonurgent cases admitted via the casualty room dropped in 2008 (Table 6) reflecting new hospital regulations. Upper Egypt had the highest number of ocular emergencies, probably reflecting a shortage of emergency services in this region.

Table 6 Ocular nonemergencies admitted via casualty room

\begin{tabular}{llll}
\hline Nonemergencies & & $\mathbf{n}$ & $\%$ \\
\hline Age (years) & $0-5$ & 288 & 29.6 \\
& $6-16$ & 335 & 34.4 \\
& $17-30$ & 115 & 11.8 \\
& $31-45$ & 84 & 8.6 \\
& $>45$ & 152 & 15.6 \\
Gender & Total & 974 & 100.0 \\
& Male & 626 & 64.3 \\
& Female & 348 & 35.7 \\
Governorate & Total & 974 & 100.0 \\
& Urban governorate & 224 & 23.0 \\
& (Cairo, Alexandria, & & \\
& Suez, Port Said) & & \\
& Upper governorate & 577 & 59.2 \\
& Lower governorate & 171 & 17.6 \\
& Frontier governorate & 1 & 0.1 \\
& (North, South Sinai, & & \\
& New Valley, Matrouh) & & \\
& Foreign & 1 & 0.1 \\
& Total & 974 & 100.0 \\
& 2004 & 105 & 10.8 \\
& 2005 & 177 & 18.2 \\
& 2006 & 218 & 22.4 \\
Year & 2007 & 327 & 33.6 \\
& 2008 & 147 & 15.1 \\
& Total & 974 & 100.0 \\
& & &
\end{tabular}

The most common ocular emergencies among males and females were open globe injuries and infective keratitis. Males had a higher incidence of lid injuries. Females showed a higher incidence of angle closure glaucoma. These data are in agreement with the reported literature. ${ }^{18}$ However, in contrast with earlier reports, ${ }^{4,12,17}$ we found a higher incidence of endophthalmitis in females. The previous literature has focused on endophthalmitis secondary to open globe injuries only, whereas our study included all cases of endophthalmitis secondary to infective keratitis.

Intraocular foreign body injuries in Egypt have a lower incidence than other developing countries, perhaps reflecting less risk of exposure to firearms. ${ }^{16,17}$ Superficial corneal foreign bodies were the most common ocular injury. Deep corneal foreign bodies were common. Posterior segment foreign bodies were about 10 -fold more common than anterior segment intraocular foreign bodies. A study from Singapore reported a two-fold higher incidence of posterior segment foreign bodies. ${ }^{15}$ Another study in Italy noted a similar incidence for both types of foreign body. ${ }^{4}$ Males represented $83.7 \%$ of ophthalmic foreign body injuries due to occupational exposure. Upper Egypt, despite being less industrialized, had the highest incidence of foreign bodies $(52.2 \%)$, and $26.78 \%$ of patients came from urban regions and $20.68 \%$ from the delta region. Lack of eye protection was the main risk factor for occupational foreign body injuries. Most of the high-velocity fragment injuries could have been prevented by use of protective polycarbonate eyewear. ${ }^{9}$

As reported previously, ${ }^{19}$ the most common reason for enucleation was a blind, disfigured painful eye. However, unlike in the Western literature, ${ }^{4,19}$ fewer primary enucleations were done for open globe injuries, mainly for medicolegal reasons. Only five severely damaged eyes with retained nonmagnetic intraocular foreign bodies were enucleated to prevent sympathetic ophthalmia. Even severely damaged eyes were repaired with excision or repositioning of the prolapsed uvea, then left to atrophy.

In conclusion, the present study shows that, over a period of 5 years, the main causes of ocular emergencies referred from all over Egypt to the ophthalmic casualty room at Cairo University Hospital are: corneal foreign bodies, open globe injuries, and infective keratitis. Deficient protective measures in workplaces seem to be the major cause of ocular injury, especially in young males. It can be assumed that health education, as well as application of safety measures and regulations, will significantly reduce the incidence of ocular injuries in the target population. 


\section{Disclosure}

The authors report no conflicts of interest in this work.

\section{References}

1. Janda DH. Prevention has everything to do with sports medicine. Clin J Sports Med. 1992;2:159-160.

2. Thylefors B. Epidemiological patterns of ocular trauma. Aust $N Z J$ Ophthalmol. 1992;20:95-98.

3. Nirmalan PK, Katz J, Tielsch JM, et al. Ocular trauma in a rural south Indian population: the Aravind Comprehensive Eye Study. Ophthalmology. 2004;111:1778-1781.

4. Cillino S, Casuccio A. A five- year retrospective study of the epidemiological characteristics and visual outcomes of patients hospitalized for ocular trauma in a Mediterranean area. BMC Ophthalmol. 2008;8:6

5. Soliman MM, Macky TA. Pattern of ocular trauma in Egypt. Graefes Arch Clin Exp Ophthalmol. 2008;246:205-212.

6. Whitcher JP, Srinivasan M, Upadhyay MP. Corneal blindness: a global perspective. Bull World Health Organ. 2001;79:214-221.

7. Tielsh JM, Parver L, Shankar. Time trends in the incidence of hospitalized ocular trauma. Arch Ophthalmol. 1989;107:519-523.

8. Byhr E. Perforating eye injuries in a western part of Sweden. Acta Ophthalmol (Copenh). 1994;72:91-97.

9. Fong LP, Taouk Y. The role of eye protection in work-related eye injuries. Aust N Z J Ophthalmol. 1995;23:101-106.
10. Desal P, Macewen CJ, Baines P, Minassian DC. Incidence of cases of ocular trauma admitted to hospital and incidence of blinding outcome. Br J Ophthalmol. 1996;80:592-596.

11. Casson RJ, Walker JC, Newland HS. Four-year review of open eye injuries at the Royal Adelaide Hospital. Clin Experiment Ophthalmol. 2002;30:15-18.

12. Koo L, Kapadia MK, Singh RP, Sheridan R, Hatton MP. Gender differences in etiology and outcome of open globe injuries. J Trauma. 2005;59:175-178.

13. Fong LP. Eye injuries in Victoria, Australia. Med J Aust. 1995;162: 64-68.

14. McGwin G Jr, Owsley C. Incidence of emergency department-treated eye injury in the United States. Arch Ophthalmol. 2005;123:662-666.

15. Wong TY, Tielsch JM. A population-based study on the incidence of severe ocular trauma in Singapore. Am J Opthalmol. 1999;128: 345-351.

16. Babar TF, Khan MT, Marwat MZ, Shah SA, Murad Y, Khan MD. Patterns of ocular trauma. J Coll Physicians Surg Pak. 2007;17:148-153.

17. Mansouri M, Faghihi H, Hajizadeh F, et al. Epidemiology of open-globe injuries in Iran: analysis of 2,340 cases in 5 years (report no. 1). Retina. 2009;29:1141-1149.

18. Bengtsson B. The prevalence of glaucoma. Br J Ophthalmol. 1981;65: 46-49.

19. Savar A, Andreoli MT, Kloek CE, Andreoli CM. Enucleation for open globe injury. Am J Ophthalmol. 2009;147:595-600. e1.
Clinical Ophthalmology

\section{Publish your work in this journal}

Clinical Ophthalmology is an international, peer-reviewed journal covering all subspecialties within ophthalmology. Key topics include: Optometry; Visual science; Pharmacology and drug therapy in eye diseases; Basic Sciences; Primary and Secondary eye care; Patient Safety and Quality of Care Improvements. This journal is indexed on

Submit your manuscript here: http://www.dovepress.com/clinical-ophthalmology-journal

\section{Dovepress}

PubMed Central and CAS, and is the official journal of The Society of Clinical Ophthalmology (SCO). The manuscript management system is completely online and includes a very quick and fair peer-review system, which is all easy to use. Visit http://www.dovepress.com/ testimonials.php to read real quotes from published authors. 